\title{
Telehealthcare for asthma: a Cochrane review
}

\author{
Susannah McLean MBBS MSc, David Chandler MBChB, Ulugbek Nurmatov MD PhD, Joseph Liu PhD, \\ Claudia Pagliari BSc PhD, Josip Car MD PhD, Aziz Sheikh MSc MD
}

\begin{abstract}
Background: Telehealthcare has the potential to provide care for long-term conditions that are increasingly prevalent, such as asthma. We conducted a systematic review of studies of telehealthcare interventions used for the treatment of asthma to determine whether such approaches to care are effective.
\end{abstract}

Methods: We searched the Cochrane Airways Group Specialised Register of Trials, which is derived from systematic searches of bibliographic databases including CENTRAL (the Cochrane Central Register of Controlled Trials), MEDLINE, Embase, CINAHL (Cumulative Index to Nursing and Allied Health Literature) and PsycINFO, as well as other electronic resources. We also searched registers of ongoing and unpublished trials. We were interested in studies that measured the following outcomes: quality of life, number of visits to the emergency department and number of admissions to hospital. Two reviewers identified studies for inclusion in our meta-analysis. We extracted data and used fixedeffect modelling for the meta-analyses.
Results: We identified 21 randomized controlled trials for inclusion in our analysis. The methods of telehealthcare intervention these studies investigated were the telephone and video- and Internet-based models of care. Meta-analysis did not show a clinically important improvement in patients' quality of life, and there was no significant change in the number of visits to the emergency department over 12 months. There was a significant reduction in the number of patients admitted to hospital once or more over 12 months (risk ratio 0.25 [95\% confidence interval 0.09 to 0.66$]$ ).

Interpretation: We found no evidence of a clinically important impact on patients' quality of life, but telehealthcare interventions do appear to have the potential to reduce the risk of admission to hospital, particularly for patients with severe asthma. Further research is required to clarify the cost-effectiveness of models of care based on telehealthcare.
Competing interests: See end of article for competing interests.

This article has been peer reviewed.

Correspondence to: Dr. Aziz Sheikh, aziz.sheikh@ed.ac.uk

CMAJ 2011. DOI:10.1503 /cmaj.101146

An earlier version of this article appeared in Cochrane Database Syst Rev 2010;(10):CD007717. Cochrane reviews are updated regularly as new evidence emerges and in response to feedback. The Cochrane Library (www.thecochranelibrary .com) should be consulted for the most recent version of the review.
$\mathrm{T}$ here has been an increase in the prevalence of asthma in recent decades, ${ }^{1-3}$ and the Global Initiative for Asthma estimates that 300 million people worldwide now have the disease. ${ }^{4}$ The highest prevalence rates $(30 \%)$ are seen in economically developed countries. $^{5-8}$ There has also been an increase in the prevalence of asthma affecting both children and adults in many economically developing and transition countries. ${ }^{9-11}$

Asthma's high burden of disease requires improvements in access to treatments. ${ }^{7,12,13}$ Patterns of help-seeking behaviour are also relevant: delayed reporting is associated with morbidity and the need for emergency care.

It is widely believed that telehealthcare interventions may help address some of the challenges posed by asthma by enabling remote delivery of care, facilitating timely access to health advice, supporting self-monitoring and medication concordance, and educating patients on avoiding trig- gers. ${ }^{14-16}$ The precise role of these technologies in the management of care for people with long-term respiratory conditions needs to be established. ${ }^{17}$

The objective of this study was to systematically review the effectiveness of telehealthcare interventions among people with asthma in terms of quality of life, number of visits to the emergency department and admissions to hospital for exacerbations of asthma.

\section{Methods}

\section{Population}

We included trials that had involved both children and adults. We were interested in randomized controlled trials done in both family practice and hospital settings. Studies had to involve participants who had received a diagnosis of asthma from a physician. Studies involving people with chronic obstructive pulmonary disease were excluded, as they are being included in a separate 
systematic review. ${ }^{17}$ No studies were excluded on the basis of age, sex, race, ethnicity or language spoken by the participants.

\section{Intervention}

Our conceptual definition of telehealthcare, as adapted from Miller, ${ }^{18}$ is "the provision of personalized healthcare at a distance." This constitutes the following three factors: information obtained from the patient, whether by conversation, video, electrocardiography, oxygen saturation, etc., that details the patient's condition; electronic transfer of this information to a health care professional over a distance; and personalized feedback tailored to the patient and provided by a health care professional who exercises clinical skills and judgement.

"At a distance" refers to health care that uses a tool of distance communication that works without the simultaneous physical presence of the participants in the interaction. According to this definition, the technology used might be the telephone, e-mail, the internet or any other networked or mobile device. The novelty or sophistication of the technology is irrelevant. Feedback from the health care professional to the patient could be synchronous or asynchronous (i.e., by store-and-forward technology, in which a patient's data are kept in an electronic repository and forwarded to a health care professional on request); we also stipulated that the health care professional should provide advice tailored to the consulting patient.

\section{Comparison}

In most instances, telehealthcare was compared with face-to-face usual care. However, in some studies, the control arm also involved an increase in the frequency or intensity of contact between health care professionals and patients.

\section{Outcomes}

The outcomes studied included process measures and clinical parameters. The key outcomes included asthma-specific quality of life as measured by the Juniper scale, the risk of one or more visits to the emergency department for asthma over 12 months, and the number of patients with one or more admissions to hospital over 12 months.

\section{Identifying studies for inclusion}

We identified randomized controlled trials using the Cochrane Airways Group Specialised Register of Trials, which is derived from systematic searches of the following bibliographic databases: CENTRAL (the Cochrane Central Register of Controlled Trials), MEDLINE, Embase, CINAHL (Cumulative Index to Nursing and
Allied Health Literature) and PsycINFO. Manual searches of respiratory journals and abstracts from meetings also contribute to the Cochrane Airways Group Specialised Register of Trials. All records in the register that had been coded as "asthma" were searched using the telehealthcare terms specified in Appendix 1 (available at www.cmaj.ca /lookup/suppl/doi:10.1503/cmaj.101146/-/DC1).

\section{Extraction and management of data}

The following data were extracted from the included studies by one reviewer and independently checked by a second reviewer: country and setting; the design of the study; the number of participants, their mean ages and the range of ages; a description of the intervention being investigated and of how the control group was managed; measures of symptoms (see Table 1 and Appendix 2 [available at www.cmaj.ca /lookup/suppl/doi:10.1503/cmaj.101146/-/DC1]); quality of life; use of the health care system, such as visits to the emergency department or admissions to hospital; cost data (from the perspective of the health care provider); monitoring of peak expiratory flow and patient diaries; patient's forced expiratory volume in one second and forced vital capacity; patient satisfaction; a description of adverse events; and patient withdrawal from the study.

\section{Analysis}

We assessed the risk of bias in each trial using the methods detailed in the Cochrane Handbook for Systematic Reviews of Interventions. ${ }^{19}$

We calculated summary statistics for our primary outcomes. We calculated risk ratios (RRs) for the dichotomous variables; for the asthmarelated quality of life score, a continuous variable, we calculated mean differences. We used the authors' published data. To create forest plots, data had to be compatible across studies. For example, for quality of life, we included only studies that reported using the Juniper scale; for visits to the emergency department, we included only studies with results that could be summarized into the variable of the number of patients with one or more visits to the emergency department over 12 months of follow-up. In this way, we produced meaningful comparative data across studies. We also included raw data in our analyses where it was supplied to us by the authors. The data from all studies (i.e., whether it was possible to include these data in the meta-analysis or not) are summarized in Appendix 2, which provides an overview of the results from all of the eligible studies.

We assessed the statistical heterogeneity between studies and the likely impact of this heterogeneity on our meta-analysis using the $I^{2}$ statis- 


\begin{tabular}{|c|c|c|c|c|c|c|c|c|c|c|c|c|c|}
\hline & 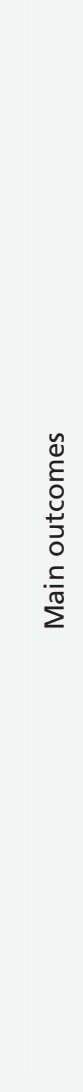 & 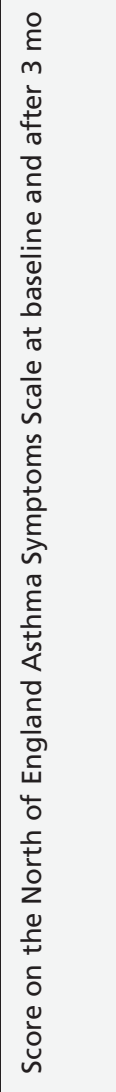 & 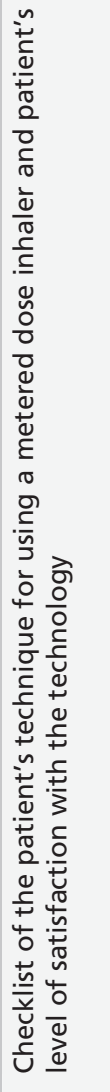 & 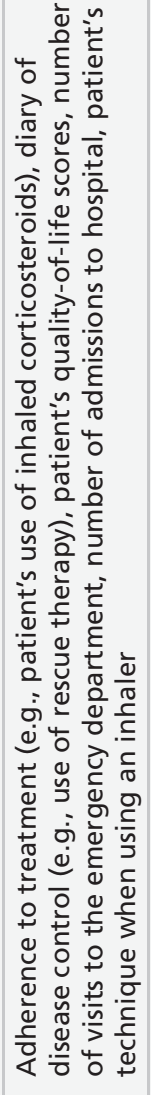 & 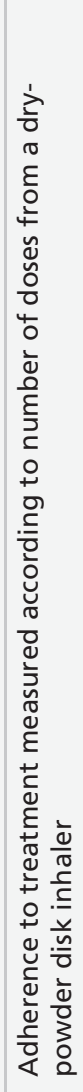 & 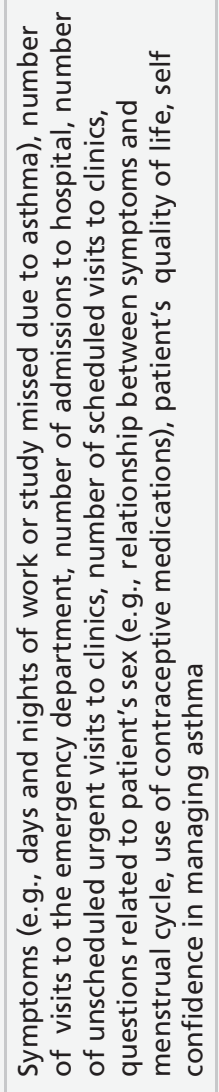 & 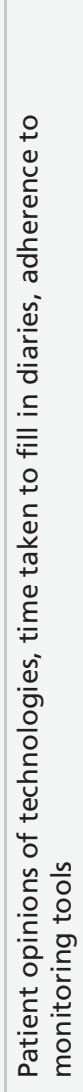 & 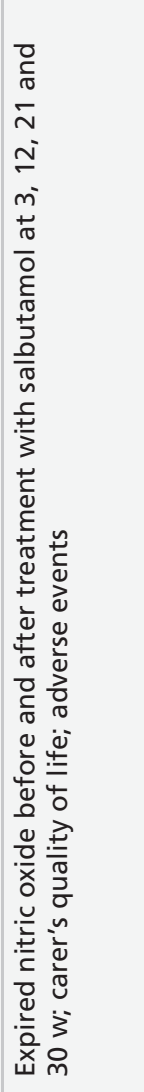 & 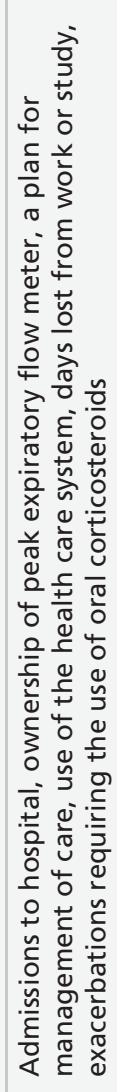 & 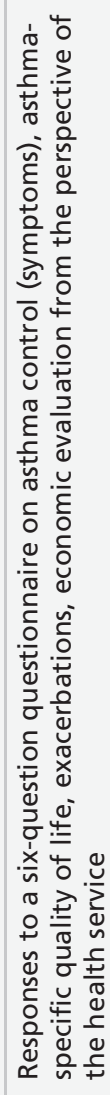 & 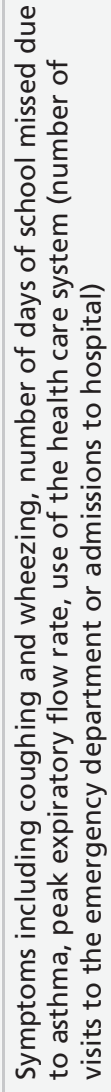 & 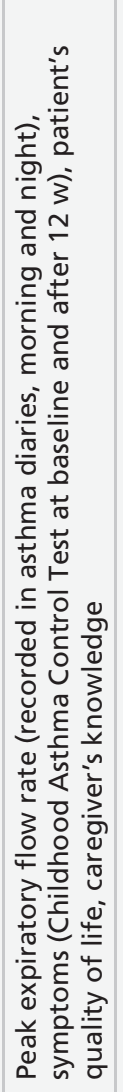 & 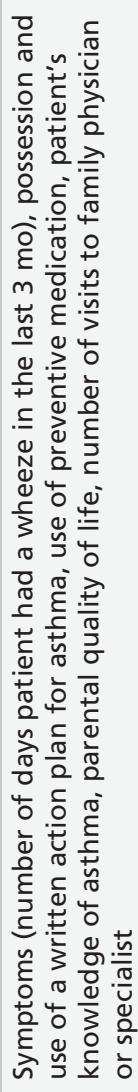 \\
\hline 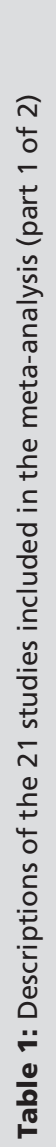 & 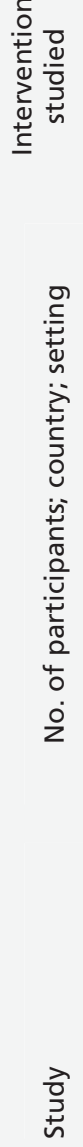 & 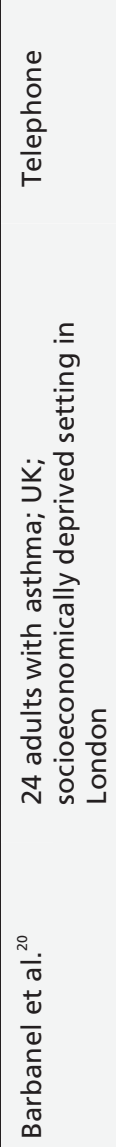 & 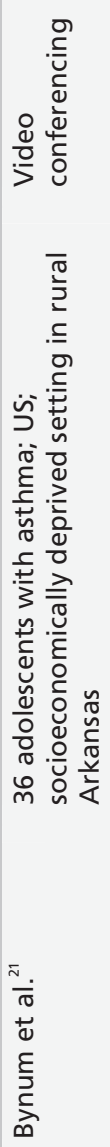 & 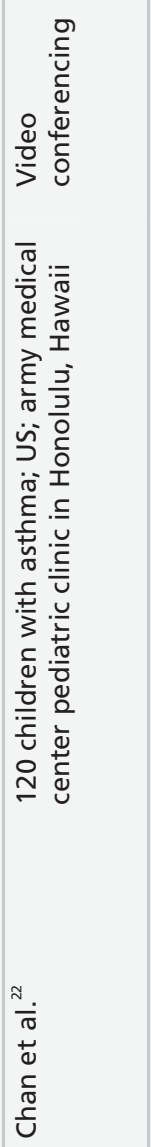 & 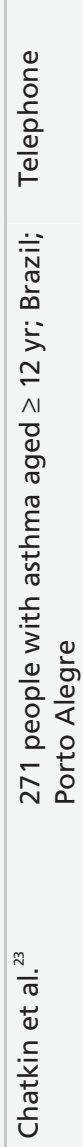 & 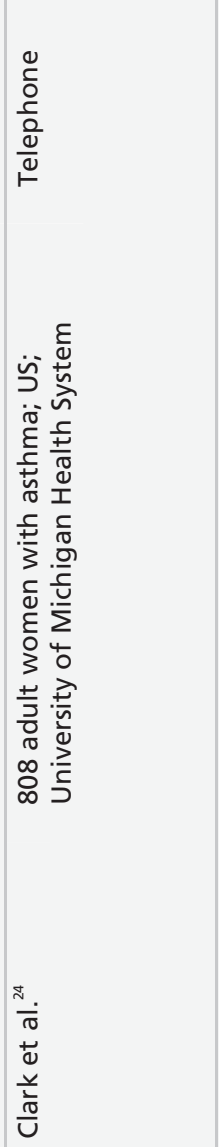 & 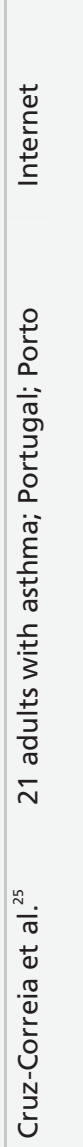 & 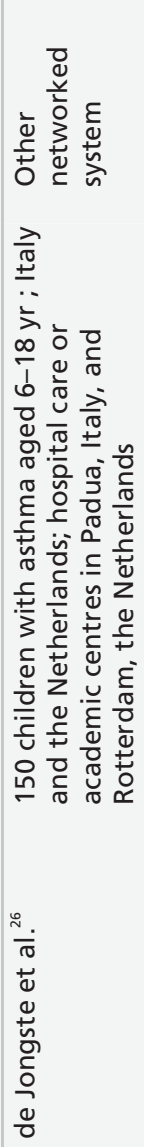 & 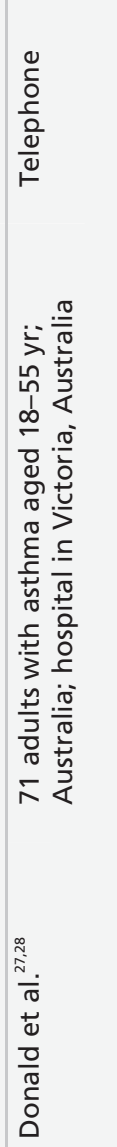 & 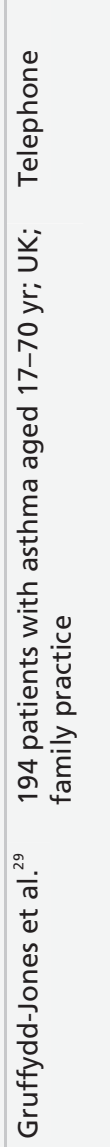 & 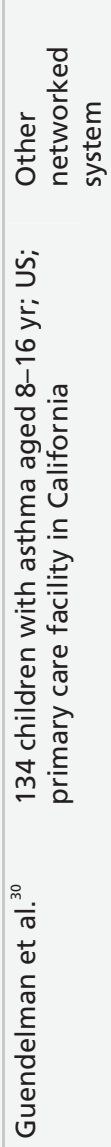 & 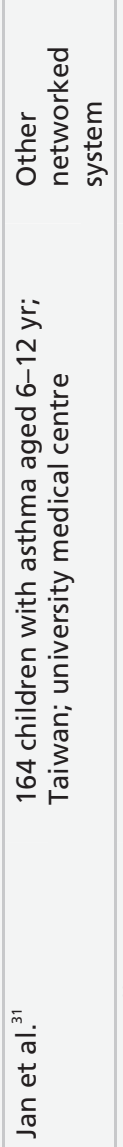 & 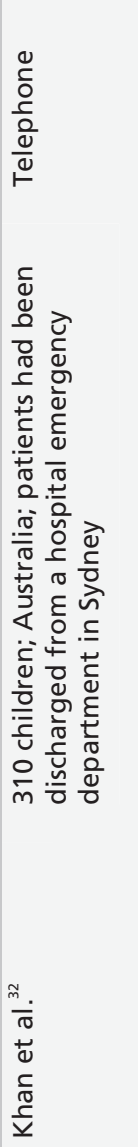 \\
\hline
\end{tabular}




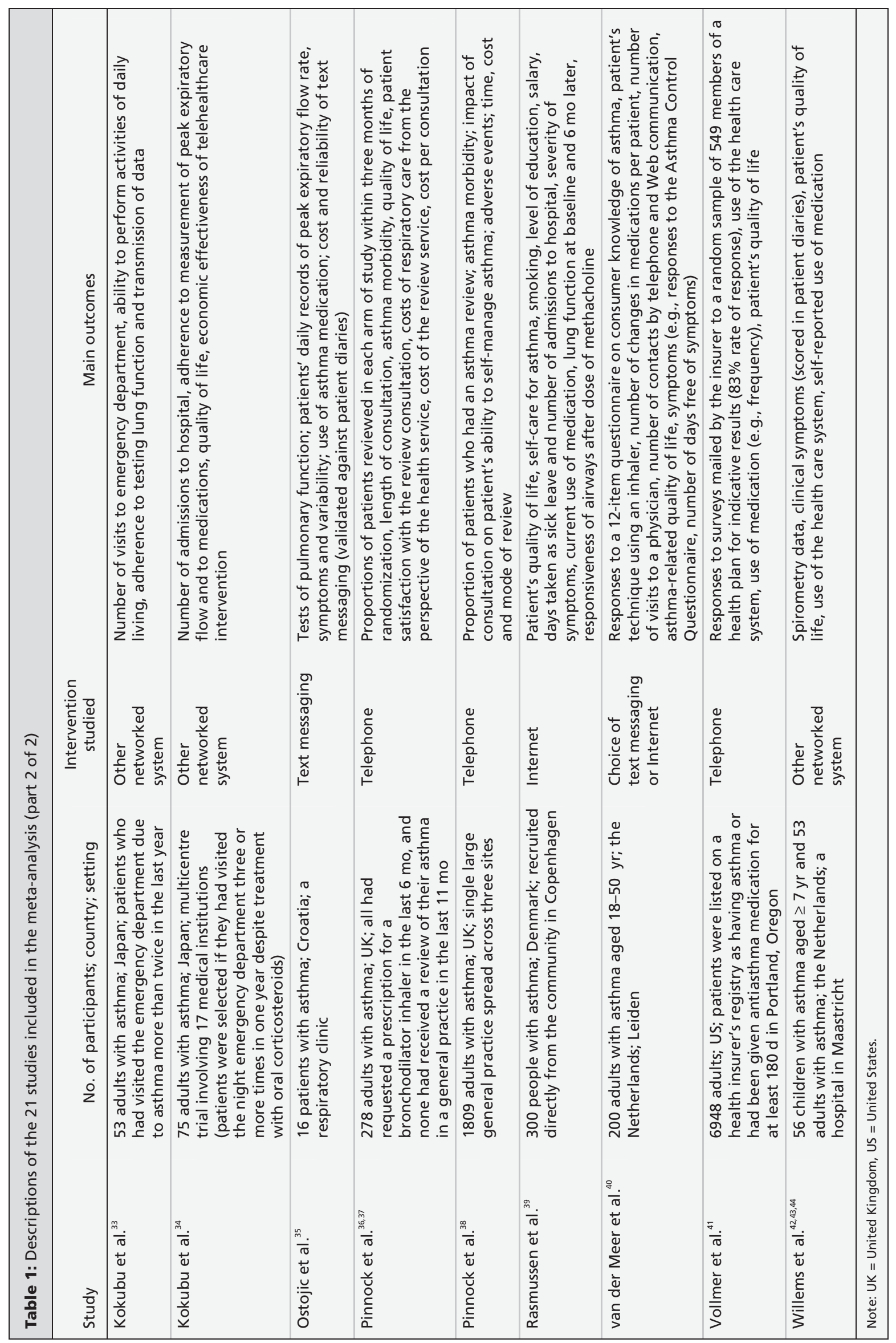


tic. ${ }^{19}$ Where ${ }^{2}$ was $40 \%$ or less, we used a fixedeffect model. We used a random-effects model if the impact of the statistical heterogenity was high (i.e., $I^{2}>40 \%$ ). Pooled data were presented graphically with forest plots. We planned subgroup analyses according to the type of technology used for telehealthcare. We used funnel plots to assess possible bias in reporting and publication (data available upon request from the authors).

\section{Results}

\section{Description of studies}

Our searches identified 525 abstracts. Initially, 76 reports had seemed possibly relevant, but 21 trials (25 reports) were included after thorough full-text review. Appendix 1 details our search strategy, which is illustrated by a PRISMA flow chart in Figure 1. A description of the studies we included is given in Table 1..$^{20-44}$ Two studies had to be translated from Japanese, and one study was translated from Italian. It was only possible to obtain partial translations of the Japanese reports. In addition, we found 14 ongoing trials that have reported preliminary findings in abstract form and 21 trials that have yet to report in any format.

\section{Telehealthcare interventions studied}

The most common model of intervention studied was an initial face-to-face introduction with follow-up exchanges between patient and health care professional using a telephone, the Internet or text messages. Seven studies applied this format. . $20,24,27,30,31,35,42^{2}$

\section{Risk of bias in the included studies}

A summary of the risk of bias in the included studies can be seen in Appendix 3 (available at www .cmaj.ca/lookup/suppl/doi:10.1503/cmaj.101146 /-/DC1).

\section{Effectiveness of telehealthcare}

The impact of telehealthcare interventions on the quality of life of people with asthma was assessed in 14 trials. $^{22,24,26,28,29,31,32,34,38-42,45}$ We did a metaanalysis of the nine studies that used Juniper's validated quality-of-life questionnaires (Figure 2A). None of the studies that looked at quality of life reported a clinically important difference (i.e., a difference of more than 0.5 points on the Juniper questionnaire). Pooling the data from nine of these studies showed a statistically significant mean difference of $0.08(95 \% \mathrm{CI}$ 0.01 to 0.16$)$.

Subgroup analyses were done for the telephone-only studies and for the studies looking at all other technologies. The five telephone- only studies pooled to give a mean difference of 0.04 (95\% CI -0.05 to 0.12 , Figure $2 \mathrm{~B})$. The four studies looking at all other technologies pooled to give a greater mean difference of 0.21 (95\% CI 0.07 to 0.34, Figure 2C); however, this difference is still less than the minimum clinically significant difference.

Ten studies (published in 11 reports) reported data on visits to the emergency department. $22,24,27,30,32,34,36,39,41,42,46$ The effect of telehealthcare interventions on the number of patients with one or more visits to the emergency department over 12 months is shown in Figure 3. This meta-analysis included five trials representing 619 patients. ${ }^{22,27,34,39,42}$ It revealed a nonsignificant increase in RR of one or more visits to the emer-

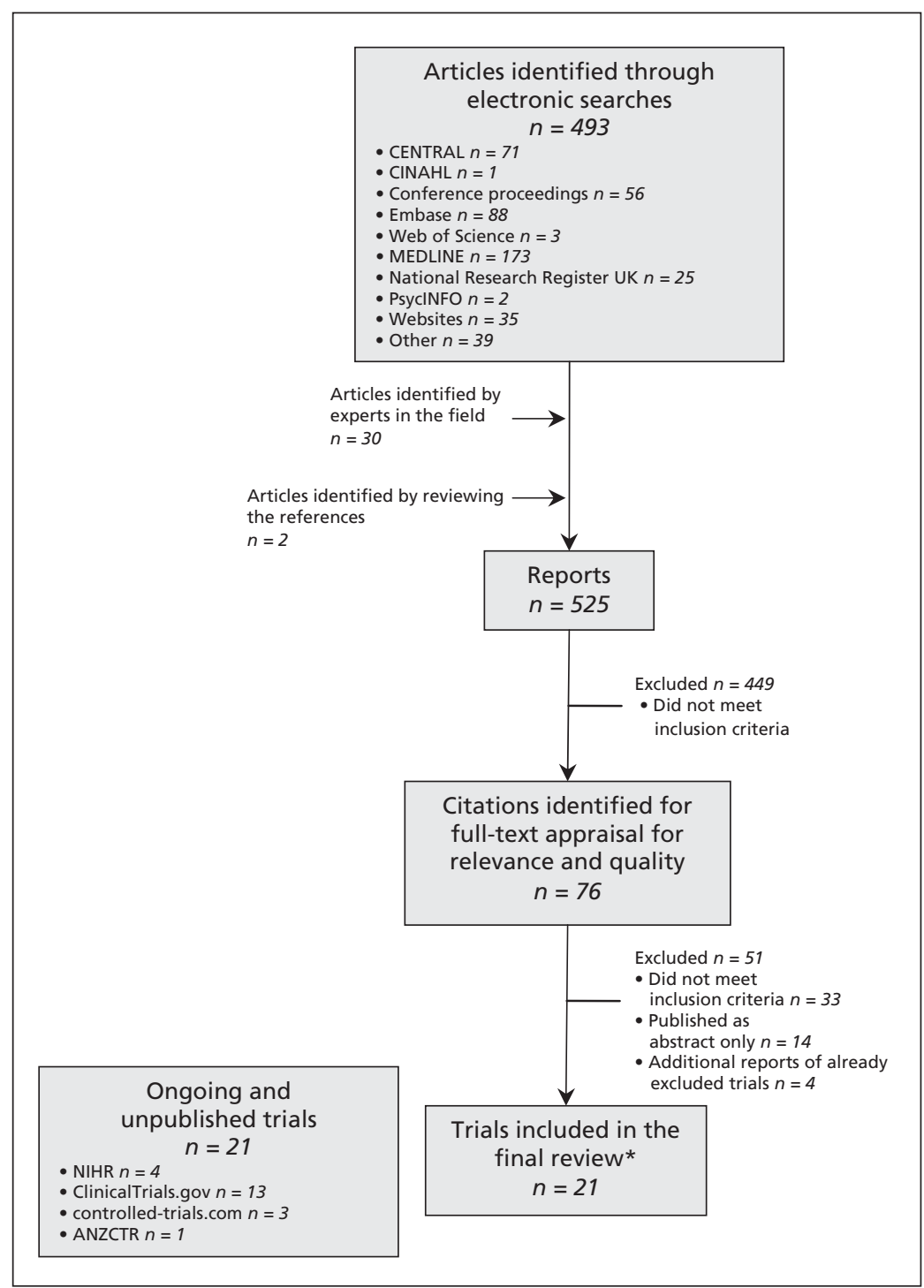

Figure 1: Identification of relevant literature on the use of telehealthcare for the treatment of asthma. ANZCTR = Australian New Zealand Clinical Trials Registry, CENTRAL $=$ the Cochrane Central Register of Controlled Trials, CINAHL = Cumulative Index to Nursing and Allied Health Literature, NIHR = National Institutes of Health Research. *The 21 trials included in the final review were published across 25 reports. 
gency department (RR 1.04 [95\% CI 0.84 to 1.28]).

Six studies presented data on admissions to hospital. ${ }^{22,28,30,34,35,39}$ For two studies, ${ }^{30,35}$ these admissions occurred over three months. For the remaining four studies, admissions to hospital were recorded as having occurred over 12 months.

For the two studies that provided data on outcomes at three months, meta-analysis showed high heterogeneity $\left(I^{2}=78 \%\right)$, so the analysis was done using random effects (RR 0.91 [95\% CI 0.07 to 12.69], Figure 4A). The confidence intervals were very wide, suggesting that it is difficult to draw any firm conclusion regarding the risk of admission to hospital over three months in the telehealthcare group versus the control group.

Meta-analysis of the four studies that reported the number of patients admitted to hospital once or more within 12 months of randomization is shown in Figure 4B (summary RR 0.25 [95\% CI 0.09 to 0.66]). This includes data from 499 patients and suggests that telehealthcare reduced the risk of admission to hospital.

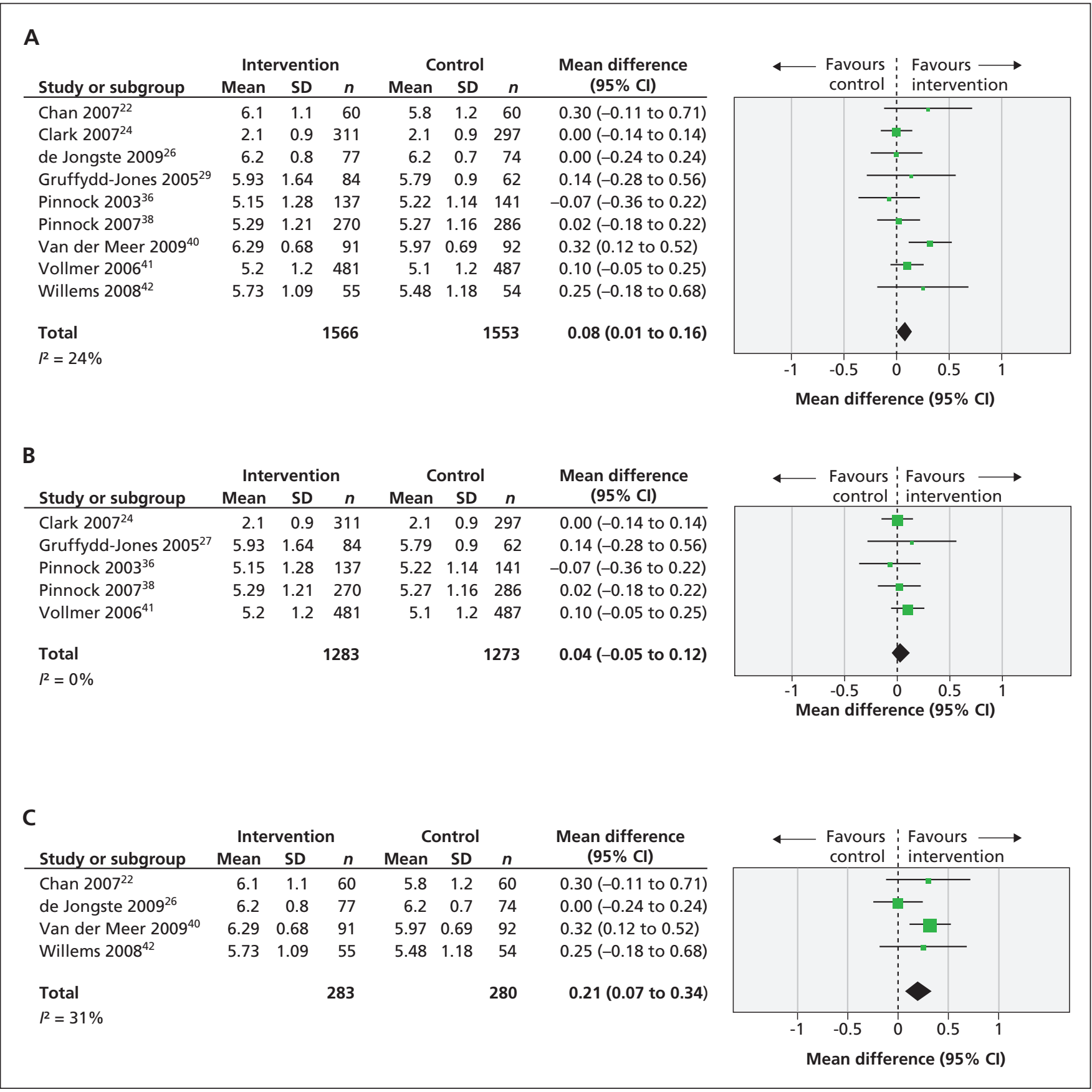

Figure 2: Forest plots of the mean differences and $95 \%$ confidence intervals (Cls) in the measurement of quality of life among patients with asthma as per Juniper's questionnaire (A), as suggested by studies investigating telehealthcare delivered by telephone only (B) and as suggested by studies investigating telehealthcare delivered by all other technologies (C). SD = standard deviation. 
The results of studies examining symptoms as an outcome are summarized in the Table of Results in Appendix 2. The results suggest that symptom scores may be improved with telehealthcare. However, in many instances, there was no difference between groups.

\section{Secondary outcomes: adverse events}

There were few adverse events reported in the studies. Two people with asthma died during the intervention arm of one study, ${ }^{29}$ but correspondence with the study's authors confirmed that these deaths were not related to asthma. This is important, as it may be expected that if telehealthcare is used as a substitute for face-to-face care, then a reduction in the intensity of health care may place a patient at risk. Larger studies are required to address this concern more fully.

\section{Interpretation}

\section{Main findings}

Our meta-analyses of the published trial evidence failed to show an appreciable impact of telehealthcare on disease-specific quality of life or risk of attendance at the emergency department

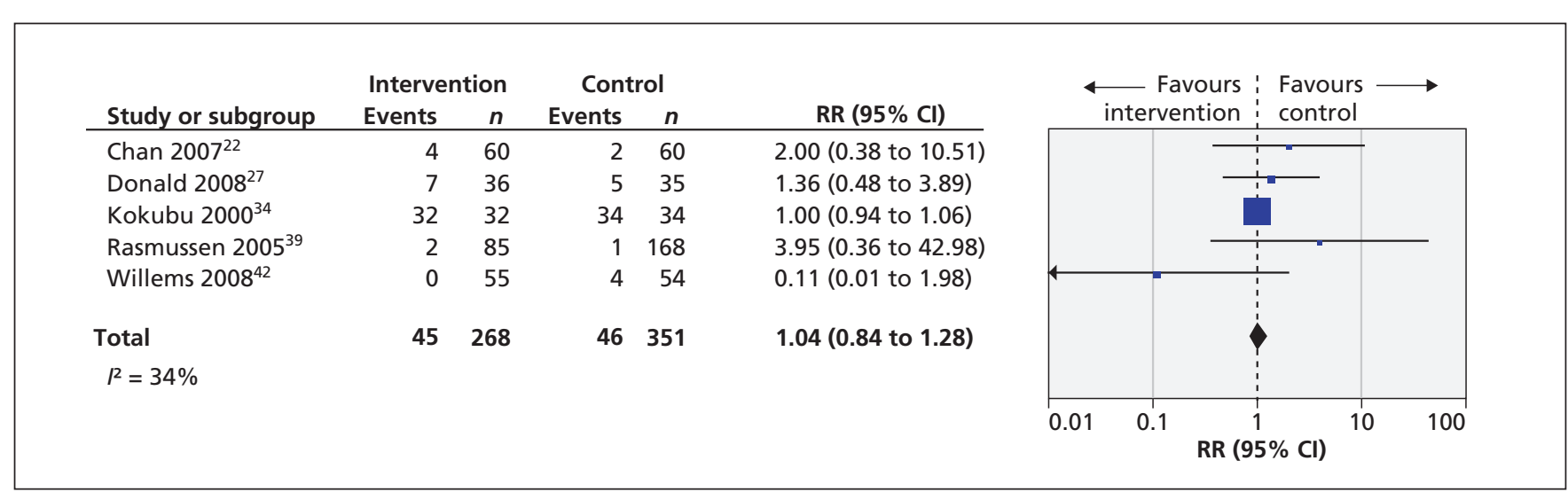

Figure 3: Forest plot of the risk ratios (RRs) and $95 \%$ confidence intervals (Cls) of the numbers of patients who visited the emergency department once or more over 12 months.

\begin{tabular}{|c|c|c|c|c|c|}
\hline \multirow[b]{2}{*}{ Study or subgroup } & \multicolumn{2}{|c|}{ Intervention } & \multicolumn{2}{|c|}{ Control } & \multirow[b]{2}{*}{ RR (95\% CI) } \\
\hline & Events & $n$ & Events & $n$ & \\
\hline Guendelman $2002^{30}$ & 4 & 62 & 1 & 60 & 3.87 (0.45 to 33.65$)$ \\
\hline Ostojic $2005^{35}$ & 2 & 8 & 7 & 8 & 0.29 (0.08 to 0.98$)$ \\
\hline $\begin{array}{l}\text { Total } \\
R^{2}=78 \%\end{array}$ & 6 & 70 & 8 & 68 & $0.91(0.07 \text { to } 12.69)^{*}$ \\
\hline
\end{tabular}

B

\begin{tabular}{lrrrrr} 
& \multicolumn{2}{c}{ Intervention } & \multicolumn{2}{c}{ Control } & \\
Study or subgroup & Events & $\boldsymbol{n}$ & Events & $\boldsymbol{n}$ & RR $(95 \% \mathrm{Cl})$ \\
\hline Chan $2007^{22}$ & 1 & 60 & 1 & 60 & $1.00(0.06$ to 15.62$)$ \\
Donald $2008^{27}$ & 1 & 31 & 6 & 29 & $0.16(0.02$ to 1.22$)$ \\
Kokubu $2000^{34}$ & 2 & 32 & 11 & 34 & $0.19(0.05$ to 0.80$)$ \\
Rasmussen $2005^{39}$ & 0 & 85 & 1 & 168 & $0.66(0.03$ to 15.91$)$ \\
Total & 4 & 208 & 19 & 291 & $\mathbf{0 . 2 5}(0.09$ to 0.66$)$ \\
$P^{2}=0 \%$ & & & & &
\end{tabular}
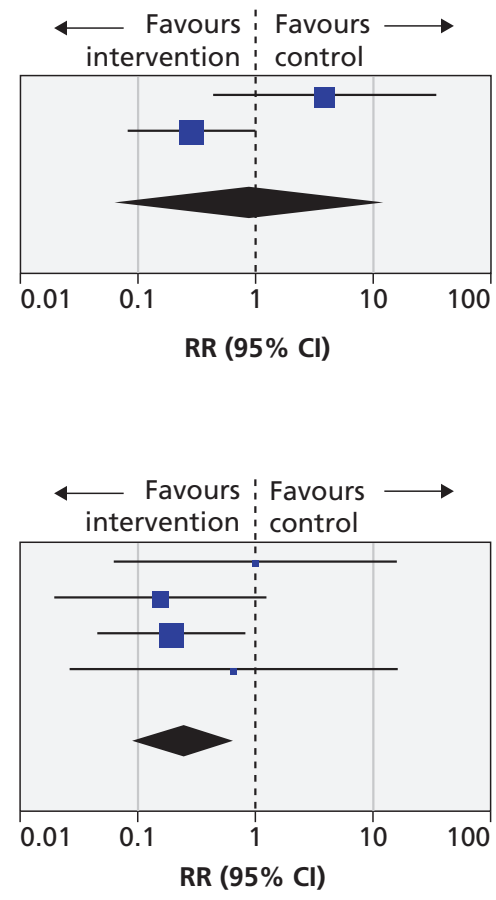

Figure 4: Forest plots of the risk ratios (RRs) and $95 \%$ confidence intervals (Cls) for the numbers of patients admitted to hospital once or more over 3 months (A), and the number of patients admitted to hospital once or more over 12 months (B).*Because of high heterogeneity, analysis was performed using a random effects model. 
for people with asthma. However, meta-analysis did show that telehealthcare may result in a reduction in the risk of admission to hospital for asthma, particularly among people at high risk.

\section{Explanation and comparison with other studies}

In contrast to our findings, a review by Duvvuri concluded that information and communication technologies can have a major role in helping a much broader section of the population of people with asthma ${ }^{47}$ The inclusion criteria of that review were broader than ours, in that the authors searched for decision support and tools of patient education in addition to the technologies in which we were interested. Studies were summarized in narrative form and no meta-analyses were attempted. Duvvuri and colleagues also drew attention to some favourable analyses of cost effectiveness and patient satisfaction. In addition, they identified the remaining hurdle of physician licensing and reimbursement when care is delivered via telehealthcare. This is particularly an issue in countries where physicians claim a fee for service from a health insurance provider, such as in Canada and the United States. We would be more cautious in recommending rapid adoption and implementation of telehealthcare strategies without further evaluation.

\section{Limitations}

The first limitation to consider is our definition of telehealthcare. Our definition rules out several interventions that others may argue do constitute telehealthcare because it stipulates that a health care professional must be actively involved with the ongoing delivery of the intervention. Our definition excluded technologies for self care and self education and websites.

Our definition also included basic technologies, particularly the telephone. We justify the telephone as a legitimate form of telehealthcare because it very effectively enables personalized health care over a distance, and it has been included in many programs of telehealthcare. Telehealthcare does not have to be new, novel or sophisticated, and the telephone is a legitimate and well-researched medium for providing telehealthcare.

In general, the level of intervention may vary in telehealthcare, with tasks delegated to less senior, less expensive health care professionals and to patients themselves for self-care when their asthma is stable. This variation may lead to more effectively tailored care. For example, telehealthcare can be supported by computer algorithms when asthma is well controlled, or it can involve more sophisticated telemonitoring when a patient's condition is less stable (i.e., "hospital at home" monitoring). The benefits of telehealthcare are mediated by education, an enhanced therapeutic relationship, more intensive monitoring of the patient and feedback. The precise mixture of these elements has not been measured by the different studies in this review; however, these elements are important and they should be studied further as per the research framework for complex interventions of the United Kingdom's Medical Research Council. ${ }^{48}$

Only four studies could be included to assess the effect of telehealthcare on admission to hospital. This is either because the other studies were too small or the follow-up period was too short to include patients who were admitted to hospital, or because the studies included only patients with mild asthma and there were no admissions to hospital. Because a large number of different scales for symptoms were used, meta-analysis across studies was not done for this outcome. Likert-type patient-satisfaction scores were reported in a number of studies and generally reflected a high level of satisfaction. However, the disadvantage of such scales is that detailed information is not gathered because of the limitations of a longitudinal scale. Complementing this type of literature with future qualitative research will help us to understand what has been missed in terms of value from the perspective of the patients and that of physicians who deal with the less severe end of the spectrum of asthma.

\section{Conclusions and implications for further research}

Telehealthcare is no worse than normal care in its ability to improve quality of life in carefully selected and triaged patients receiving primary and secondary care. It does not appear more able to improve quality of life than routine models of care, nor does it appear to reduce the number of visits a patient makes to the emergency department. Studies with larger intervention and control groups are needed to confirm these results with precision. We did, however, find that admissions to hospital decreased. It may be useful to consider focusing certain telehealthcare interventions on groups with higher risk. Further research should look at stratifying the risk of admission to hospital and relating it to the effectiveness of telehealthcare intervention.

Many of the patients in the control arms of the studies received enhanced face-to-face care for their asthma rather than usual care, so it was particularly challenging to show the benefits of telehealthcare in these comparisons. Future studies should make comparisons with usual care to best judge whether telehealthcare offers any improvement, or equivalence studies should be done if 
the population in the control group receives enhanced care. Considerably more research is also needed to investigate the cost effectiveness of telehealthcare-centred models of care.

\section{References}

1. Pearce N, Sunyer J, Cheng S, et al. Comparison of asthma prevalence in the ISAAC and the ECRHS. Eur Respir J 2000; 16:420-6.

2. Asher MI, Montefore S, Bjorkstén B, et al. Worldwide time trends in the prevalence of symptoms of asthma allergic rhinoconjunctivitis and eczema in childhood: ISAAC Phases One and Three repeat muli-country cross-sectional surveys. Lancet 2006;368 733-43.

3. Anderson HR, Gupta R, Strachan DP, et al. 50 years of asthma: UK trends from 1955 to 2004. Thorax 2007;62:85-90.

4. Masoli M, Fabian D, Holt S, et al. Global burden of asthma. GINA [The Global Initiative for Asthma]; 2003.

5. The future of asthma. Lancet 1997;350:1113.

6. Anandan C, Nurmatov U, Sheikh A. Is the prevalence of asthma declining, systematic review of epidemiological studies. Allergy 2010;65:152-67.

7. Simpson CR, Sheikh A. Trends in the epidemiology of asthma in England: a national study of 333,294 patients. $J$ R Soc Med 2010;103:98-106.

8. Punekar YS, Sheikh A. Establishing the incidence and prevalence of clinician-diagnosed allergic conditions in children and adolescent using routinely collected data from general practices. Clin Exp Allergy 2009;39:1209-16.

9. Marks GB. Geographical heterogeneity of asthma. Int J Epidemiol 2001;30:179-80.

10. Stewart AW, Mitchell EA, Pearce N, et al. ISAAC. The relationship of per capita gross national product to the prevalence of symptoms of asthma and other atopic diseases in children (ISAAC). Int J Epidemiol 2001;30:173-9.

11. Weiland SK, Bjorkstén B, Brunekreef B, et al. Phase II of the International Study of Asthma and Allergies in Childhood (ISAAC II): rationale and methods. Eur Respir J 2004;24: 406-12.

12. Gupta R, Sheikh A, Strachan D, et al. Burden of allergic disease in the UK: secondary analyses of national databases. Clin Exp Allergy 2004;34:520-6.

13. Anandan C, Gupta R, Simpson C. C F, Sheikh A. Epidemiology and disease burden from allergic disease in Scotland: analyses of national databases. J R Soc Med 2009;102:431-42.

14. Car J, Sheikh A. Email consultations in healthcare: 1- scope and effectiveness. BMJ 2004;329:435-8.

15. Car J, Sheikh A. Email consultation in healthcare: 2- acceptability and safe application. BMJ 2004;329:439-42.

16. McLean S, Sheikh A. Does telehealthcare offer a patient-centred way forward for the community-based management of longterm respiratory disease? Prim Care Respir J 2009;18:125-6.

17. McLean S, Liu J, Pagliari C, et al. Telehealthcare for chronic obstructive pulmonary disease [protocol]. Cochrane Database Syst Rev 2008; updated 2011 Feb. 21.

18. Miller EA. Solving the disjuncture between research and practice, telehealth trends in the 21st Century. Health Policy 2007; 82:133-41.

19. Higgins J, Green S, editors. Cochrane handbook for systematic reviews of interventions. Hoboken: John Wiley \& Sons; 2009.

20. Barbanel D, Eldridge S, Griffiths C. Can a self-management programme delivered by a community pharmacist improve asthma control? A randomised trial. Thorax 2003;58:851-4.

21. Bynum A, Hopkins D, Thomas A, et al. The effect of telepharmacy counselling on metered-dose inhaler technique among adolescents with asthma in rural arkansas. Telemed J E Health 2001; 7:207-17.

22. Chan DS, Callahan CW, Hatch-Pigott VB, et al. Internet-based home monitoring and education of children with asthma is comparable to ideal office-based care: results of a 1-year asthma inhome monitoring trial. Pediatrics 2007;119:569-78.

23. Chatkin JM, Blanco DC, Scaglia N, et al. Impact of a low-cost and simple intervention in enhancing treatment adherence in a Brazilian asthma sample. J Asthma 2006;43:263-6.

24. Clark NM, Gong ZM, Si JW, et al. A randomized trial of a selfregulation intervention for women with asthma. Chest 2007;132: 88-97.

25. Cruz-Correia R, Fonseca J, Lima L, et al. Web-based or paperbased self-management tools for asthma-patients' opinions and quality of data in a randomized crossover study. Stud Health Technol Inform 2007;127:178-89.
26. de Jongste JC, Carraro S, Hop WC, et al. Daily telemonitoring of exhaled nitric oxide and symptoms in the treatment of childhood asthma. Am J Respir Crit Care Med 2009;179:93-7.

27. Donald KJ, McBurney H, Teichtahl H, et al. A pilot study of telephone based asthma management. Aust Fam Physician 2008; 37:170-3.

28. Donald KJ, McBurney H, Teichtahl H, et al. Telephone based asthma management; Financial and individual benefits. Aust Fam Physician 2008;37:272-75

29. Gruffydd-Jones K, Hollinghurst S, Ward S, et al. Targeted routine asthma care in general practice using telephone triage. $\mathrm{Br} J$ Gen Pract 2005;55:918-23.

30. Guendelman S, Meade K, Benson M, et al. Improving asthma outcomes and self-management behaviors of inner-city children: a randomized trial of the Health Buddy interactive device and an asthma diary. Arch Pediatr Adolesc Med 2002;156: 114-20.

31. Jan RL, Wang JY, Huang MC, et al. An internet-based interactive telemonitoring system for improving childhood asthma outcomes in Taiwan. Telemed J E Health 2007;13:257-68.

32. Khan MSR, O'Meara M, Stevermuer TL, et al. Randomized controlled trial of asthma education after discharge from an emergency department. J Paediatr Child Health 2004;40:674-7.

33. Kokubu F, Suzuki H, Sano Y, Kihara N, Adachi M. Telemedicine system for high-risk asthmatic patients. Arerugi 1999; 48:700-12.

34. Kokubu F, Nakajima S, Ito K, et al. Hospitalisation reduction by an asthma tele-medicine system. Arerugi 2000;49:19-31.

35. Ostojic V, Cvoriscec B, Ostojic SB, et al. Improving asthma control through telemedicine: A study of short-message service. Telemed J E Health 2005;11:28-35.

36. Pinnock H, Bawden R, Proctor S, et al. Accessibility, acceptability, and effectiveness in primary care of routine telephone review of asthma: pragmatic, randomised controlled trial. BMJ 2003;326:477-9.

37. Pinnock H, McKenzie L, Price D, et al. Cost-effectiveness of telephone or surgery asthma reviews: economic analysis of a randomised controlled trial. Br J Gen Pract 2005;55:119-24.

38. Pinnock H, Adlem L, Gaskin S, et al. Accessibility clinical effectiveness and practice costs of providing a telephone option for routine asthma reviews: phase IV controlled implementation study. Br J Gen Pract 2007;57:714-22.

39. Rasmussen LM, Phanareth K, Nolte H, et al. Internet-based monitoring of asthma: A long-term, randomized clinical study of 300 asthmatic subjects. J Allergy Clin Immunol 2005;115: 1137-42.

40. van der Meer V, Bakker M, van den Hour W, et al. Internetbased self management plus education compared with usual care in asthma. Ann Intern Med 2009;151:110-20.

41. Vollmer WM, Kirshner M, Peters D, et al. Use and impact of an automated telephone outreach system for asthma in a managed care setting. Am J Manag Care 2006;12:725-33.

42. Willems DC, Moore MA, Jenkins JJ. The effectiveness of nurseled telemonitoring of asthma results of a randomized controlled trial. J Eval Clin Pract 2008;14:600-9.

43. Willems DCM, Joore MA, Hendriks JJE, et al Cost-effectiveness of a nurse-led telemonitoring intervention based on peak expiratory flow measurements in asthmatics: Results of a randomised controlled trial. Cost Eff Resour Alloc 2007;5:10.

44. Willems DC, Joore MA, Hendriks JJ, et al. Process evaluation of a nurse-led telemonitoring programme for patients with asthma. J Telemed Telecare 2007;13:310-7.

45. Pinnock H, Sheikh A, Bawden R, et al. Cost effectiveness of telephone vs face to face consultations for annual asthma review: randomised controlled trial in UK primary care [abstract]. Eur Respir J 2003;22(Suppl 45).

46. Phanareth K, Rasmussen L, Nolte H, et al. Using the internet as a tool for the management of asthma disease. Eur Respir J 2002; 20(Suppl 38):54s.

47. Duvvuri VR, Jianhhong W. Information and communication technology developments in asthma management: a systematic review. Indian J Med Sci 2007;61:221-41.

48. Craig P, Dieppe P, Macintyre S, et al. Developing and evaluating complex interventions: the new Medical Research Council guidance BMJ. 2008;337:a1655. doi: 10.1136/bmj.a1655.

Competing interests: Susannah McLean has received an honorarium for lectures and has been reimbursed for travel and meetnig expenses related to speaking engagements about telehealthcare. Claudia Pagliari has received a grant from the National Health Service Connecting for Health Evaluation Program. Aziz Sheikh was involved in some of 
the studies included in this review, so he did not take part in the assessment of their quality during our analysis. He has received a grant from the National Health Service Connecting for Health Evaluation Programme. He had full access to all relevant data and had final responsibility for the decision to submit this report for publication. This report is independent research supported by the National Institute of Health Research. The views expressed in this publication are those of the authors and not necessarily those of the National Health Service, the National Institute of Health Research or the Department of Health. No other competing interests were declared.

Affiliations: From the Allergy and Respiratory Research Group (McLean, Chandler, Nurmatov, Liu, Sheikh) and the eHealth Research Group (Pagliari, Sheikh), Centre for Population Health Sciences, the University of Edinburgh, Edinburgh, UK; and the eHealth Unit (Car), Imperial College London, London, UK
Contributors: Aziz Sheikh conceived of the review. Susannah McLean wrote the protocol with oversight from Joseph Liu, Claudia Pagliari and Josip Car. Susannah McLean and David Chandler searched for and selected the studies used. Susannah McLean and Ulugbek Nurmatov extracted the data. Susannah McLean wrote up the results. Josip Car commented on the draft. All of the authors approved the final manuscript submitted for publication.

Funding: This work was supported by grants from the Chief Scientist's Office Scotland, the National Health Service Connecting for Health Evaluation Programme (NHS CFHEP 001) and the Edinburgh Medical Research Council Trials Methodology Hub (G0800803). Susannah McLean was supported by a National Health Service Education for Scotland Clinical Academic Fellowship. The funding agencies had no role in designing or conducting this study, the collection, management, analysis and interpretation of the data, or the preparation, review or approval of the manuscript. 